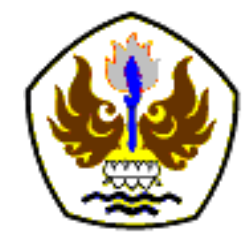

INFOMATEK

Volume 20 Nomor 1 Juni 2018

\title{
ANALISIS RESIKO KESEHATAN LINGKUNGAN UDARA AMBIEN TERHADAP PENGGUNA JALAN DAN MASYARAKAT SEKITAR PADA RUAS JALAN IR. SUKARNO SURABAYA
}

\author{
Taty Alfiah ${ }^{\left.{ }^{*}\right)}$ dan Evi Yuliawati ${ }^{2)}$ \\ 1) Jurusan Teknik Lingkungan, \\ Fakultas Teknik Sipil Perencanaan, Institut Teknologi Adhi Tama Surabaya \\ 2) Jurusan Teknik Industri, \\ Fakultas Teknologi Industri, Institut Teknologi Adhi Tama Surabaya
}

\begin{abstract}
Abstrak: Keberadaan Jl. Ir. Soekarno atau Merr, Surabaya meningkatkan akses menuju kawasan Surabaya timur yang merupakan area perumahan dan permukiman. Kemacetan lalu lintas pada Jl. Ir. Soekarno Merr, Surabaya semakin meningkat, terutama didominasi oleh kendaraan pribadi, baik roda 2 maupun roda 4 karena belum tersedia angkutan umum. Penelitian dilaksanakan pada ruas JI. Ir. Soekarno Surabaya, dari peremapatan Stikom hingga perempatan Semolowaru, meliputi volume lalu lintas pada pagi dan sore hari, mengukur $\mathrm{CO}, \mathrm{Pb}$, $\mathrm{PM}_{10}$, dan kebisingan, pengumpulan data melalui kuisioner terhadap terhadap populasi beresiko (populasi yang melewati jalan (komuter), populasi yang beraktifitas dan populasi yang bertempat tinggal/bermukim). Kesimpulan penelitian adalah kualitas udara ambien pada ruas Jl. Ir. Soekarno, masih memenuhi baku mutu udara ambien nasional untuk parameter $\mathrm{Pb}, \mathrm{CO}, \mathrm{PM}_{10}$ dan bising. Analisis Resiko Kesehatan Lingkungan udara ambien $\mathrm{Jl}$ Ir. Soekarno atau Merr terhadap populasi komuter (pengguna jalan yang hanya melintas), populasi road side yaitu pekerja dan penghuni masih aman. Perhitungan karakterisasi resiko (RQ) menunjukkan hasil $R Q<1$ untuk karbon monoksida $(\mathrm{CO})$, timbal $(\mathrm{Pb})$ dan partikulat $\mathrm{PM}_{10}$. Intreptasi ARKL untuk ketiga pencemar udara - $\mathrm{CO}$, $\mathrm{PM}_{10}$ dan $\mathrm{Pb}$ masih dalam tingkat resiko "Aman" bagi komuter dan populasi road side untuk saat ini.
\end{abstract}

Kata kunci: udara ambien, Analisis Resiko Kesehatan Lingkungan

\section{PENDAHULUAN}

\subsection{Latar Belakang}

Jalan Ir. Soekarno atau Merr, Surabaya meningkatkan akses menuju kawasan Surabaya timur yang merupakan area perumahan dan permukiman. Keberadaan $\mathrm{Jl}$. Ir. Soekarno mendorong terjadinya perubahan

\footnotetext{
*) taty09@itats.ac.id
}

Pertama diterima : 15 Januari 2018

Direvisi : 2 Februari 2018

Disetujui untuk publikasi: 2 Februari 2018 tata guna lahan di sepanjang sisi jalan tersebut, menjadi pertokoan, rumah makan, perkantoran, mini market, maupun apartemenhotel. Kemacetan lalu lintas pada JI. Ir. Soekarno Merr, Surabaya semakin meningkat, terutama didominasi oleh kendaraan pribadi, baik roda 2 maupun roda 4 karena belum tersedia angkutan umum. 
Beberapa penyebab kemacetan lalu lintas di perkotaan antara lain (Ali Alhadar, 2011 [1]): layanan transportasi umum yang buruk, peningkatan jumlah kendaraan bermotor, arus urbanisasi, infrastruktur jalan masih kurang, fasilitas pendukung jalan kurang, dan rendahnya kesadaran masyarakat untuk tertib berlalu lintas. Kemacetan di kota Surabaya disebabkan oleh pertambangan volume kendaraan yang tidak seimbang dengan kapasitas jalan, kesadaran masyarakat menggunakan transportasi umum masih kurang, transportasi umum belum memenuhi standar layak, masyarakat tidak tertib berlalu lintas, PKL memakan badan jalan serta kurangnya pengaturan polantas pada titik kemacetan saat jam macet (Aloisius de Rozari, 2015 [2]).

Emisi kendaraan bermotor berbeda antara satu daerah dengan daerah lainnya disebabkan oleh perbedaan desain jalan maupun kondisi lalu lintas. Besarnya emisi kendaraan bermotor di jalan dipengaruhi oleh tiga faktor yaitu volume total kendaraan bermotor, karakteristik kendaraan bermotor, kondisi umum lalu lintas saat itu (Jalaluddin, 2013 [3]).

Semakin tinggi beban pencemar semakin tinggi pula konsentrasi udara ambien, ditunjukkan dengan nilai korelasi positif pada analisis regresi (Nurhadi Hodijah dkk, 2014
[4]). Kualitas udara ambien berpengaruh terhadap terhadap kesehatan masyarakat. Polusi udara berdampak terhadap kesehatan (Brunekreef, dkk., 2002 [5]), (Kampa and Castanas, 2008 [6]). Polutan udara dapat mendorong terjadinya penyakit kardiovaskuler (Metzger, dkk., 2004 [7]), memiliki efek terhadap fertilitas pria (Michele De Rosa, dkk., 2003 [8]).

Untuk melindungi masyarakat, perlu dilakukan pemantauan kualitas udara ambien dan menyampaiakan status kualitas udara ambien kepada masyarakat. Salah satu cara pemantauan kualitas udara ambien di daerah perkotaan/urban adalah melalui pemantauan kualitas udara ambien otomatis (Air Quality Monitoring System/AQMS) yang menampilkan angka tanpa satuan pada papan/layar display. Namum data pemantauan kualitas udara ambien belum menunjukkan korelasinya terhadap kesehatan masyarakat. Analisis resiko masih belum banyak digunakan untuk melakukan kebijakan pengelolaan kualitas udara ambien dalam rangka melindungi kesehatan masyarakat

\section{METODOLOGI}

Penelitian dilakukan dengan mengumpulkan data lapangan, analisis laboratorium, perhitungan. Lokasi penelitian pada ruas Jl. Ir. 
Analisis Resiko Kesehatan Lingkungan Udara Ambien terhadap Pengguna Jalan dan Masyarakat Sekitar pada Ruas Jalan Ir Sukarno Surabaya

Soekarno Surabaya, dari perempatan Stikom hingga perempatan Semolowaru.

Tahapan pelaksanaan penelitian meliputi: perhitungan jumlah dan jenis kendaraan yang melewati Jl. Ir Soekarno pada jam puncak pagi dan sore hari ; mengukur parameter $\mathrm{CO}, \mathrm{Pb}$, $\mathrm{PM}_{10}$, dan kebisingan ; serta pengumpulan data umur, berat badan, jenis kelamin durasi terpajan, frekuensi terpajan, profesi, keluhan kesehatan melalui wawancara dan kuisioner pada populasi beresiko, yaitu populasi yang melewati jalan (komuter), populasi yang bekerja (beraktifitas) dan populasi yang bertempat tinggal (bermukim) dilanjutkan perhitungan analisis resiko kesehatan lingkungan.

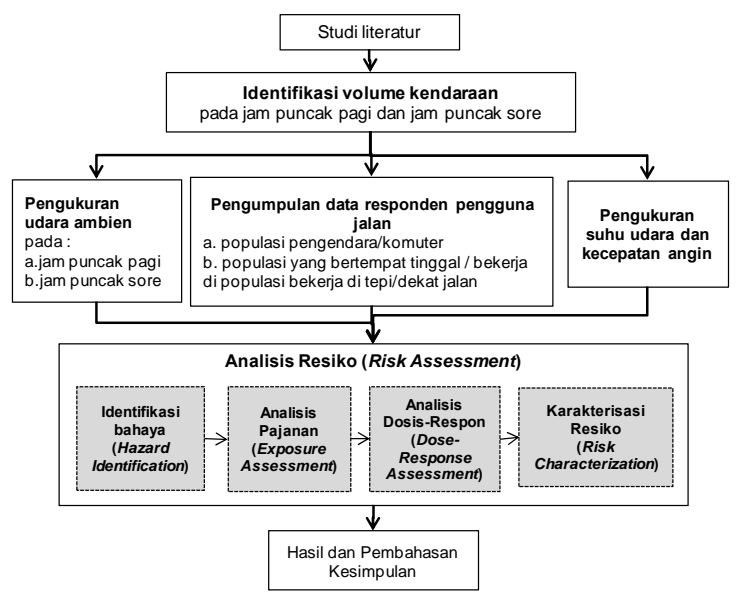

Gambar 1.

Tahapan pelaksanaan penelitian
Persamaan matematis untuk menghitung tingkat risiko $(\mathrm{RQ}=$ Risk Quotient $=\mathrm{RQ})$ senyawa kimia pencemar non karsinogen adalah (K. F. R. Liu, 2015 [9]; Syahrul, 2014 [10]; Haryono Setyo Huboyo, 2007 [11]; Ujang Soleh Suryaman, 2011 [12]; M.M.Mokhtar dkk., 2013 [13]; Kurnia Dwi C.R, 2014 [14]; Ece Almunjiat, 2016 [15]):

$$
\mathrm{RQ}=\frac{\mathrm{I}}{\mathrm{RfC}}
$$

Dimana: $\mathrm{RQ}=$ tingkat resiko $; \mathrm{I}=$ intake harian kronis (mg/kg.hari) ; RfC = konsentrasi referensi (mg/kg.hari).

Tingkat risiko dinyatakan dalam angka atau bilangan desimal tanpa satuan. Tingkat risiko dikatakan AMAN bilamana $\mathbf{R Q} \leq 1$.

Intake $\left(I_{n k}\right)$ pada jalur pemajanan inhalasi (terhirup) agen pencemar non karsinogenik dapat dihitung dengan persamaan :

$$
I_{n k}=\frac{C \times R \times t_{E} \times f_{E} \times D_{t}}{W_{b} \times t_{a v g}}
$$

Dimana : $I_{\mathrm{nk}}=$ asupan (intake) $(\mathrm{mg} / \mathrm{kg}$ berat badan.hari) ; $\mathrm{C}=$ konsentrasi senyawa kimia pencemar di udara $\left(\mathrm{mg} / \mathrm{m}^{3}\right) ; \mathrm{R}=$ laju asupan ; laju inhalasi $\left(\mathrm{m}^{3} / \mathrm{jam}\right.$ - untuk inhalasi) ; untuk dewasa $=0,83 \mathrm{~m}^{3} / \mathrm{jam} ;$ untuk anak-anak (6- 
12 tahun) $=0,5 \mathrm{~m}^{3} / \mathrm{jam} ; \mathrm{t}_{\mathrm{E}}=$ lama pajanan (jam/hari) ; $f_{E}=$ frekuensi pajanan (hari/tahun) (350 hari/tahun untuk nilai default residensial) Dt $=$ durasi paparan (tahun) ; (30 tahun untuk nilai default residensial) $; \mathrm{Wb}=$ berat badan individu $(\mathrm{kg}) ; \mathrm{t}_{\mathrm{ave}}=$ periode waktu rata-rata (hari) ; (Dt x 365 hari/tahun)

\section{ANALISIS DAN PEMBAHASAN}

Gambaran volume lalu lintas Jl Ir Sukarno pada pagi hari ( jam 06 - 09) dan sore hari (15 - 18) dinyatakan pada Gambar 2.
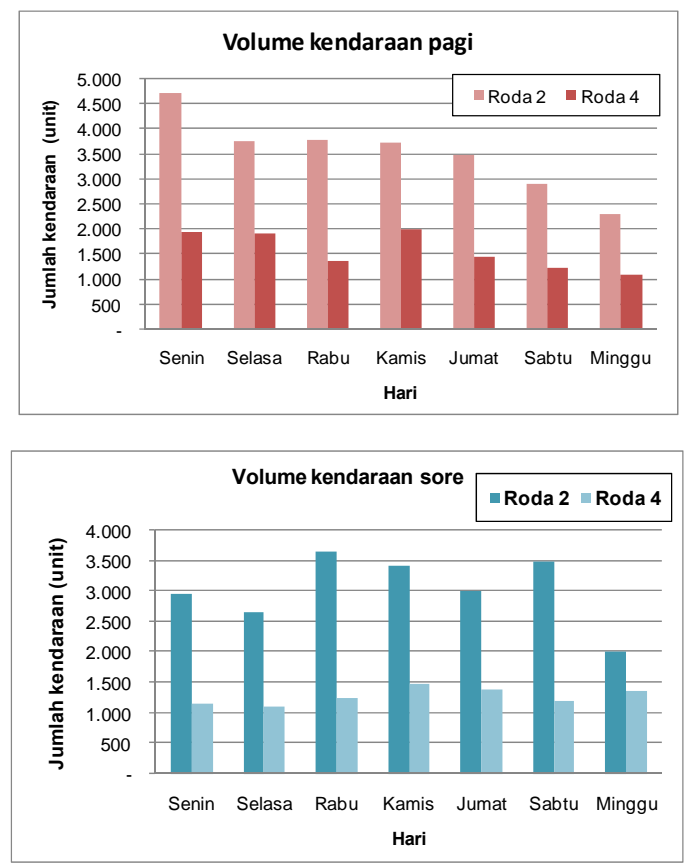

Gambar 2.

Volume kendaraan yang melintas JI. Ir Sukarno Surabaya pada pagi dan sore hari
Tabel 1.

Kualitas udara ambien di Jl. Ir. Soekarno, Surabaya

\begin{tabular}{|c|c|c|c|c|c|c|c|c|}
\hline \multirow{2}{*}{ Waktu } & \multicolumn{2}{|c|}{ Kebisingan (dB.A) } & \multicolumn{2}{|c|}{$\mathrm{CO}($ (ug/Nm3) } & \multicolumn{2}{|c|}{$\mathrm{Pb}(\mathrm{mg} / \mathrm{L})$} & \multicolumn{2}{|c|}{ PM10 (gr/Nm3) } \\
\hline & Nilai & Rata-rata & Nilai & Rata-rata & Nilai & Rata-rata & Nilai & Rata-rata \\
\hline \multirow{4}{*}{ Pagi hari } & 21,167 & \multirow{4}{*}{21,826} & 0,338 & \multirow{4}{*}{0,382} & 0,056 & \multirow{4}{*}{0,075} & 70,242 & \multirow{4}{*}{71,106} \\
\hline & 21,570 & & 0,352 & & 0,074 & & 70,610 & \\
\hline & 22,114 & & 0,409 & & 0,078 & & 71,440 & \\
\hline & 22,453 & & 0,428 & & 0,092 & & 72,130 & \\
\hline \multirow{4}{*}{ Sore hari } & 26,870 & \multirow{4}{*}{27,776} & 0,416 & \multirow{4}{*}{0,492} & 0,071 & \multirow{4}{*}{0,09425} & 165,103 & \multirow{4}{*}{172,183} \\
\hline & 27,264 & & 0,437 & & 0,089 & & 173,621 & \\
\hline & 28,421 & & 0,54 & & 0,091 & & 171,284 & \\
\hline & 28,549 & & 0,576 & & 0,126 & & 178,722 & \\
\hline
\end{tabular}

Analisis resiko kesehatan lingkungan perlu dilakukan pada lingkungan yang mulai mengalami pencemaran akibat aktifitas manusia. Populasi manusia yang berada pada lingkungan tercemar akan menerima pajanan senyawa kimia pencemar ke dalam tubuhnya. Masuknya senyawa kimia pencemar dalam tubuh manusia dapat menyebabkan gangguan kesehatan. Untuk mengkaji berapa besar potensi bahaya dari senyawa kimia pencemar, maka dilakukan analisis resiko kesehatan lingkungan. Hasil analisis dapat dimanfaatkan untuk membuat kebijakan dalam rangka melakukan tindakan untuk melindungi kesehatan masyarakat umum.

Sedangkan tingkat resiko $\mathrm{Pb}, \mathrm{PM} 10$ dan $\mathrm{Co}$ dapat ditunjukkkan melalui Gambar 3 dan 4. 
Analisis Resiko Kesehatan Lingkungan Udara Ambien terhadap Pengguna Jalan dan Masyarakat Sekitar pada Ruas Jalan Ir Sukarno Surabaya

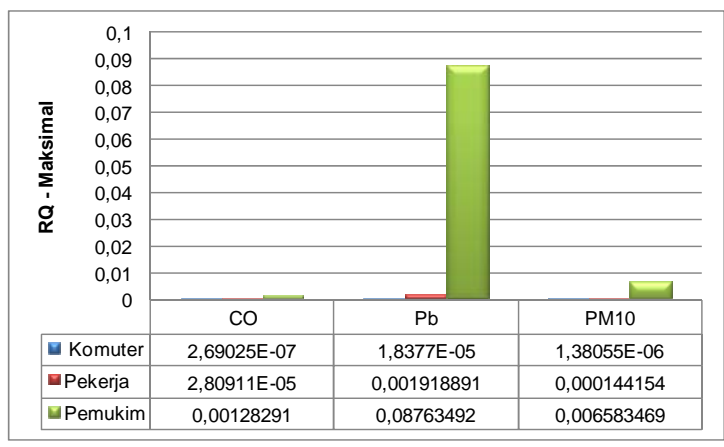

Gambar 3.

Karakterisasi resiko pajanan (RQ) maksismal berdasarkan jenis agen parameter pencemar udara

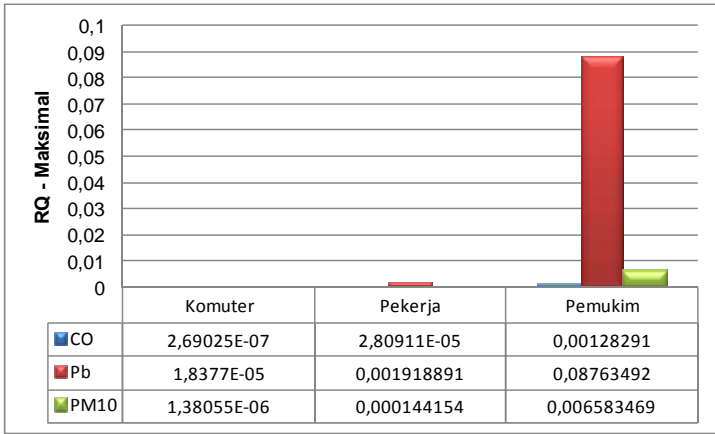

Gambar 4.

Karakterisasi resiko pajanan (RQ) maksismal berdasarkan jenis responden

\section{KESIMPULAN}

Kesimpulan penelitian adalah sebagai berikut :

1. Parameter udara ambien $\mathrm{CO}, \mathrm{Pb}, \mathrm{PM} 10$ dan kebisingan masih di bawah baku mutu udara ambien dan baku mutu bising.
2. Analisis resiko kesehatan lingkungan udara ambien JI Ir. Soekarno atau Merr terhadap populasi komuter (pengguna jalan yang hanya melintas), populasi road side yaitu pekerja dan penghuni masih aman. Perhitungan karakterisasi resiko (RQ) menunjukkan hasil $\mathrm{RQ}<1$ untuk karbon monoksida $(\mathrm{CO})$, timbal $(\mathrm{Pb})$ dan partikulat PM10. Intreptasi ARKL untuk ketiga pencemar udara - CO, PM10 dan $\mathrm{Pb}$ masih dalam tingkat resiko AMAN bagi komuter dan populasi road side untuk saat ini.

\section{DAFTAR PUSTAKA}

[1] Ali Alhadar, 2011, Analisis Kinerja Jalan dalam Upaya Mengatasi Kemacetan Lalu Lintas Pada Ruas Simpang Bersinyal di Kota Palu, Jurnal SMARTek, Vol. 9 No. 4. Nopember 2011: 327 - 336 ; http://download.portalgaruda.org/article.p hp?article $=10782 \&$ val $=750$

[2] Aloisius de Rozari, Yudi Hari Wibowo, 2015, Faktor-faktor yang menyebabkan kemacetan lalu lintas di jalan utama Kota Surabaya (Studi Kasus Di Jalan Ahmad 
Yani Dan Raya Darmo Surabaya), http://jurnal.untag-

sby.ac.id/index.php/jpap/article/view/393

[3] Jalaluddin, Asri Gani, Darmadi, 2013, Analisis Karakteristik Emisi Gas Buang Pada Sarana Transportasi Roda Dua Kota Banda Aceh, Jurnal Teknik Mesin Unsyiah, volume 1, nomor 4 (Desember 2013) ISSN 2301-8224, http://www.jurnal.unsyiah.ac.id/JTM/articl e/view/1445

[4] Nurhadi Hodijah, Bintal Amin, Mubarak; 2014, Estimasi Beban Pencemar Dari Emisi Kendaraan Bermotor di Ruas Jalan Kota Pekanbaru, Dinamika Lingkungan Indonesia, Juli 2014, Volume 1, Nomor 2, p 71-79, ISSN 2356-2226, http://ejournal.unri.ac.id/index.php/DL/arti cle/view/2300]

[5] Bert Brunekreef; Stephen T Holgate; 2002, Air pollution and health, THE LANCET, Vol 360, October 19, 2002 , http://www.consano.ch/AtherosclerosisAir PollutionAndHealthLancet2002.pdf

[6] Marilena Kampa, Elias Castanas, 2008, Human health effects of air pollution,
Environmental Pollution 151 (2008) 362367, http://edge.rit.edu/content/P13625/ public/Reference\%20Documents/Human \%20Health\%20Effects\%20of\%20Air\%20 Pollution\%20Kampa\%20and\%20Castana s.pdf

[7] Metzger, Kristi Busico; Tolbert, Paige E.; Klein, Mitchel; Peel, Jennifer L.; Flanders, W Dana; Todd, Knox; Mulholland, James A.; Ryan, P Barry; Frumkin, Howard, 2004; Ambient Air Pollution and Cardiovascular Emergency Department Visits ; Epidemiology: January 2004 Volume 15 - Issue 1 - pp 46-56. http://journals.Iww.com/epidem/toc/2004/ 01000

[8] Michele De Rosa, Stefano Zarrilli, Luigi Paesano, Umberto Carbone, Bartolomeo Boggia, Mario Petretta, Antonella Maisto, Francesca Cimmino, Giancarmelo Puca, Annamaria Colao and Gaetano Lombardi, 2003, Traffic pollutants affect fertility in men, Human Reproduction Vol.18, No.5 pp. 1055-1061, 2003. http://humrep.oxfordjournals.org/content/1 8/5/1055.full.pdf+html 
[9] K. F. R. Liu, K. Yeh, M.-J. Hung, C.-W. Chen, and Y.-S. Shen, 2015, Health Risk Analysis of Indoor Air Pollution, International Journal of Environmental Science and Development, Vol. 6, No. 6, June 2015, DOI: 10.7763/IJESD.2015.V6. 638, http://www.ijesd.org/vol6/638-S0007. pdf , (diakses : 07/08/2016 18:31)

[10] Syahrul Basri, Emmi Bujawati., Amansyah, M., Habibi, dan Samsiana; 2014; Analisis Risiko Kesehatan Lingkungan (Model Pengukuran Risiko Pencemaran Udara Terhadap Kesehatan), Jurnal Kesehatan, Volume VII No. 2/2014, p. 427-442; http://journal.uin-

alauddin.ac.id/index.php/kesehatan/articl e/view/61/34

[11] Haryono Setyo Huboyo, Syafrudin Syafrudin, 2007, Analisis resiko konsentrasi debu (TSP) dan timbal $(\mathrm{Pb})$ di pinggir jalan terhadap kesehatan manusia studi kasus Kota Yogyakarta, TEKNIK - Vol. 28 No. 2 Tahun 2007, ISSN 0852-1697, http://ejournal.undip. ac.id/index.php/teknik/article/view/2115/1 860

[12] Ujang Soleh Suryaman dan Abdur Rahman, 2011, Wilayah Aman Bagi Pemukiman Dekat Tambang Batu Kapur: Suatu Pendekatan Manajemen Risiko, Jurnal Ekologi Kesehatan Vol. 10 No 4, Desember $2011: 256$ - 266

[13] M.M.Mokhtar et al., 2013, Health Risk Assessment in Coal-Fired Power Plant in Malaysia, Proceedings of the 6th International Conference on Process Systems Engineering (PSE ASIA) 25 - 27 June 2013, Kuala Lumpur. http://www.sps.utm.my/download/PSEAsi a2013-25.pdf

[14] Kurnia Dwi C.R dan Abdul Rohim T, Penilaian risiko paparan asap kendaraan bermotor pada polantas Polrestabes Surabaya tahun 2014, The Indonesian Journal of Occupational Safety and Health, Vol. 3, No. 1 Jan-Jun 2014: 4657; http://journal.unair.ac.id/downloadfullpapers-k3118a2e13dcfull.pdf

[15] Ece Almunjiat, Yusuf Sabilu, Ainurrafiq ainurrafiq; Analisis Risiko Kesehatan 
Infomatek Volume 20 Nomor 1 Juni 2018 : 27 - 34

akibat Pajanan Timbal $(\mathrm{Pb})$ melalui Jalur Inhalasi pada Operator di Stasiun Pengisian Bahan Bakar Umum (SPBU) di Kota Kendari tahun 2016 (studi di SPBU tipulu, Wua-wua, Anduonohu dan SPBU Lepo-Lepo), JIMKESMAS Jurnal IImiah
Mahasiswa Kesehatan Masyarakat, Vol 1, No 3 (2016), http://ojs.uho.ac.id/ index.php/JIMKESMAS/article/view/1209/ 856 